\title{
ARTICLE
}

\section{Development of a fleet of mobile units for Accident Monitoring of Internal Contamination: application in the frame of Fukushima accident}

\author{
Didier Franck ${ }^{*}$, Frédéric Parre, Cécile Challeton-de Vathaire, Eric Blanchardon, David Broggio, \\ Xavier Moya, Didier Viltard and Michèle Agarande \\ IRSN - Institut de Radioprotection et de Sûreté Nucléaire, IRSN/PRP-HOM/SDI/LEDI, BP-17, 92262 Fontenay-aux-Roses, France
}

\begin{abstract}
In the event of an accident involving radioactive material, there could potentially be a large number of people requiring internal contamination monitoring. To answer to this challenge, the IRSN, the French institute for radiological protection and nuclear safety, has developed since 2007 a fleet of 10 body counting mobile units: 8 light and heavy emergency units and 2 expertise mobile units, unique in Europe, allowing on-site monitoring of up to 2500 people per day. Their use for the follow up of French nationals coming back from Japan after the Fukushima Accident is described and discussed.
\end{abstract}

Keywords: mobile units; in vivo monitoring; internal contamination; emergency; radiological accident

\section{Introduction}

In the event of an accident involving radioactive material, there could potentially be a large number of people who require monitoring for internal contamination. If the release contains radionuclides which emit high-energy gamma rays then the most suitable mean of providing this monitoring is whole body counting. The advantage of a mobile system over fixed in vivo monitoring facilities is that the latter may be to a considerable distance from the accident. Besides, the mobile system will allow members of the public who may have been exposed because of their proximity to the accident to be monitored with the minimum of delay and inconvenience. Like for medical surveillance [1], rapid monitoring is also important because many radionuclides which may be present are short-lived and the seriousness of the accident will need to be quickly assessed.

To answer to these two challenges, the IRSN, the French institute for radiological protection and nuclear safety, has developed since 2007 a fleet of mobile unit, unique in Europe, able to monitoring on-site up to 2500 people per day and capable to answer to any radiological emergencies involving internal contamination of gamma emitters:

- 4 light emergency body counting mobile units: to carry out a fast trial of contaminated / non contaminated people

- 4 heavy emergency body counting mobile units: for a better management of the psychosocial phase of the crisis

*Corresponding author. Email: Didier.franck@irsn.fr
- 2 expertise body counting mobile units: to carry out activity assessment of contaminated individuals in case of complex contamination and expertises for nuclear workers.

In a first part, these systems are presented in function of the urgency of the situation. In a second part the summary of the controls made by the IRSN on French citizens coming back from Japan in the aftermath of Fukushima accident. The results of the measurements and the internal dose calculations are presented and discussed

\section{General presentation}

\subsection{The 4 light emergency mobile units}

The goal of these mobile units is to carry out a fast trial (contaminated / non contaminated) of people. The unit has been built on standard Peugeot Boxer minivan (Figure 1). Technical details and performances are given in Franck et al. [2]. Basically this minivan is equipped with 4 seats type measurement geometry. Each in vivo monitor consists of two $\mathrm{NaI}(\mathrm{Tl})$, independently adjustable to allow movement up and down and at various distances from the subject, and may be used concurrently for most subjects. A first detector (3"x 3") used for whole body measurement is positioned so that the detector centre is on the subject's thorax and a second detector (2"x 1") above the thyroid. An example of whole body and thyroid measurement of a subject is shown in Figure 2. As the system is designed to be readily transported, it was not possible to use the massive shielding often used for fixed whole body counters. Instead, a shadow shield arrangement has been 
used, which places the shielding where it is most effective, i.e. around both detectors and in the back of the seat. The counting time is fixed at 10 minutes but can be adjusted in function of the urgency and the number of people to be controlled.

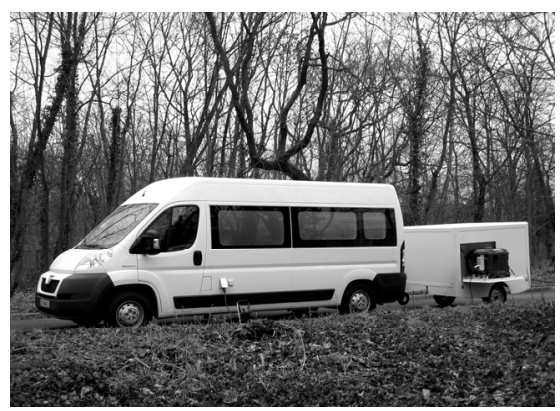

Figure 1. General view of the light emergency mobile unit and its trailer.

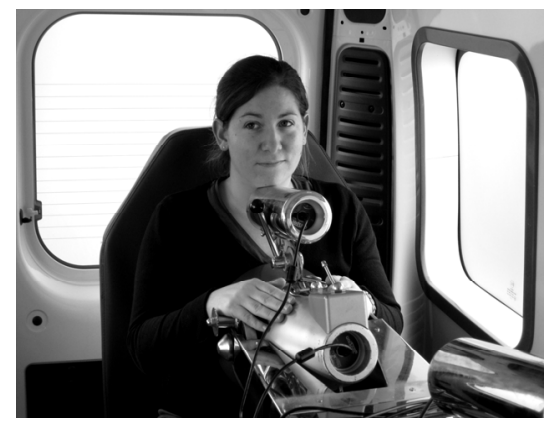

Figure 2. Whole body and thyroid measurements of a subject in the emergency minivan.

\subsection{The 4 emergency heavy mobile units}

In emergency situations it will be also necessary to perform direct measurements on people for reassurance of the public, even if such measurements would not be necessary from a strict radiation protection point of view. As a matter of fact, the additional emergency means based on shelters have been developed. A general view of the shelter placed on its truck for road transportation is shown in Figure 3. Their goal, in addition to help the trial of people, will be to perform a better management of the psychosocial phase of the crisis.

As shown in Figure 4, 10 seats have been installed in a shelter, equipped with the same in vivo systems and communication system as the minivans allowing the control of around 2000 people a day.

The major difference of these mobile units is, in addition to be transported by truck or train, the possibility of transportation by air, allowing a very fast travelling everywhere in France or in the world if required in case of important crisis.

\subsection{The 2 expertise mobile units}

To complete this fleet, 2 expertise mobile units have been developed. They are equipped with more sophisticated in vivo systems able to answer to crisis involving more complex contaminations (such as actinides or multi- gamma contaminations).

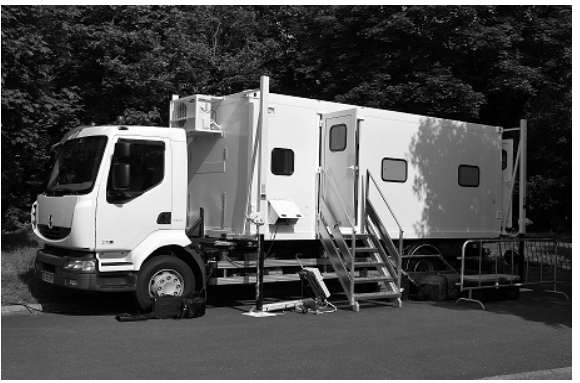

Figure 3. General view of the heavy emergency mobile unit (the shelter is placed on its truck for road transportation).

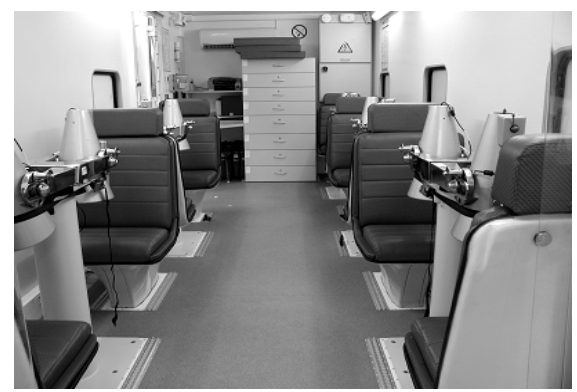

Figure 4. Inner view of the heavy emergency mobile unit (shelter).

Technical details and performances are given in Franck et al. [1]. A general view of this expertise truck is given in Figure 5. Basically, this vehicle is organized as a fixed in vivo laboratory with two main rooms: a first room with toilets serves as an office and is equipped with a bench for conditioning samples if urinary excreta are collected and a second room for in vivo monitoring. The truck is also equipped with a dressing room with paper gowns to prevent any contamination of the in vivo monitoring system.

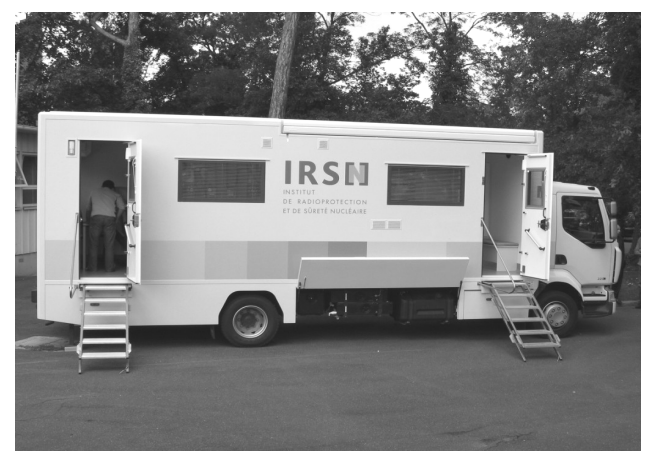

Figure 5. General view of the expertise mobile unit.

In order to gain optimum sensitivity and obtain a large range of energy, two Broad Energy high purity Germanium (BEGe) detectors equipped with Electrically Refrigerated Cryostat (Cryo-Pulse ${ }^{\circledR}$ ) from Canberra are used allowing 3 geometries of measurements: whole body, thyroid and lung (Figure 6).

These expertise mobile units were used for the follow-up of French nationals coming back from Japan 


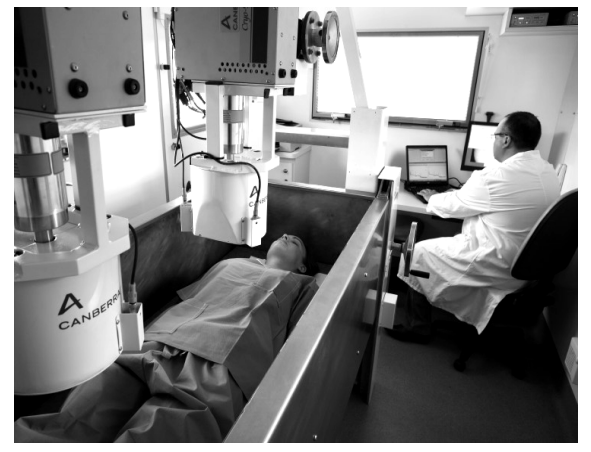

Figure 6. Inner view of the expertise mobile unit. Example of a whole body measurement.

\section{Results of the controls made by the IRSN on French nationals in the aftermath of the Fukushima accident}

Within the first 48 hours which followed the accident, the IRSN was contacted on one hand, by company doctors in charge of the follow-up of staff members, flight crews, journalists sent to Japan to cover at first the Tsunami events and, on the other hand, French members of the public living in Japan envisaging their temporary or definitive return in France. All these persons wanted to know whether they have been contaminated or not by radioactive elements during their stay in Japan.

To quantify the internal contamination, and then to assess the internal dose received, in vivo examinations including two measurements were carried out with the 2 expertise mobile units presented above: one in the whole body (counting time: 20 minutes) and one at the level of the thyroid (counting time: 15 minutes). If these measurements were found positives, the assessment of the committed effective dose and the equivalent dose to the thyroid were systematically calculated and sent to the health services taking care of the exposed people.

\subsection{In vivo examinations}

At the end of 2011, the IRSN had carried out 536 in vivo examinations on 268 persons, including 95 journalists, 62 staff members operating in Japan, 36 flight crews and 75 members of the public (Figure 7) [3].

Figure 8 shows that $77 \%$ of in vivo measurements made on journalisms were carried out during the 3 first weeks after the accident whereas for members of the publics there were two waves: the first one in the 2 first weeks and the second one during the summer period where families came back for vacation in France. For staff members, the number of exams increased because of companies' requirements for controls of their workers coming back from Japan.

The different radionuclides detected between March $11^{\text {th }}$ to April $30^{\text {th }}$ are indicated in Figure 9. As expected, during the first month it was I-131 which was found the most frequently and also Te-132 and I-132. After this period essentially traces of I-131 ( $1^{\text {st }}$ month in 5 people) and Cs-137 (till October in 10 people).

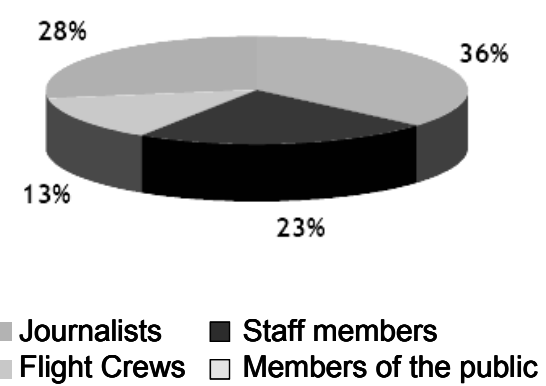

Figure 7. Repartition of in vivo monitoring carried out between March and December 2011 in function of measured people.

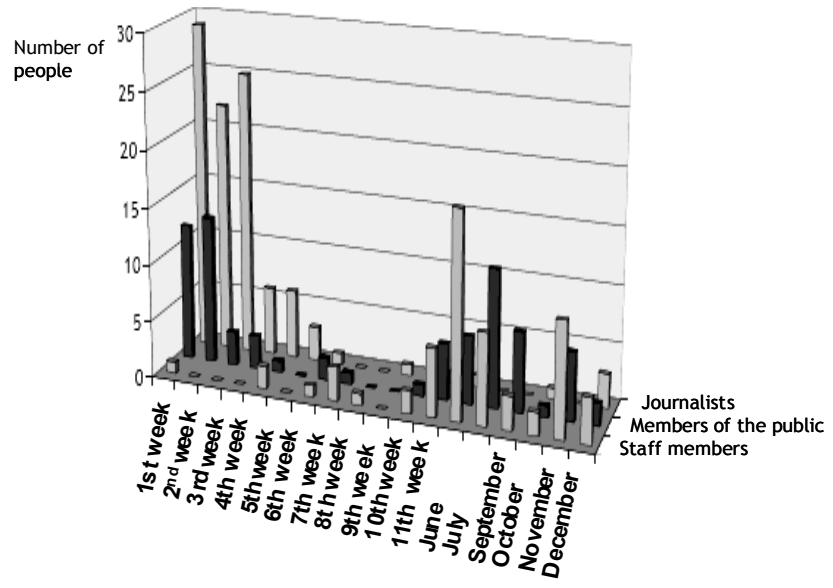

Figure 8. Evolution of in vivo examinations between March and December 2011.

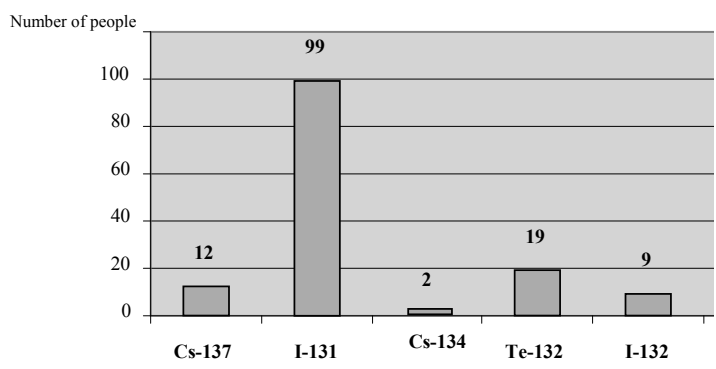

Figure 9. Radionuclides found on people between March $11^{\text {th }}$ to April $30^{\text {th }}, 2011$.

\subsection{Doses assessment}

The incorporated activities, the committed effective doses and doses equivalent to the thyroid were calculated with the IMBA ${ }^{\circledR}$ software (Integrated Modules for Bioassay Analysis) [5]. The applied biokinetic models of the publication ICRP 56 [6] was used for caesium and iodine isotopes and ICRP 67 [7] for the tellurium. Furthermore, for dose calculation the period and the time spent in Japan as well as the location of the people were considered.

The Figures $\mathbf{1 0}$ and $\mathbf{1 1}$ show respectively the distribution of committed effective doses and equivalent doses to the thyroid calculated for the measured people for whom the in vivo exam was found positive (negative exam means that no contamination was detected) [3].

For the most exposed person, a French national living in Japan, the committed effective dose was estimated 
lower than $0.1 \mathrm{mSv}$ and the equivalent dose to the thyroid lower than $1.4 \mathrm{mSv}$. For comparison, in France, the annual committed effective dose limit for the public is $1 \mathrm{mSv}$ and the equivalent dose to the thyroid initiating the process of stable iodine administration is $50 \mathrm{mSv}$ [4]. At such exposure levels, there was thus no sanitary consequence for the French nationals.

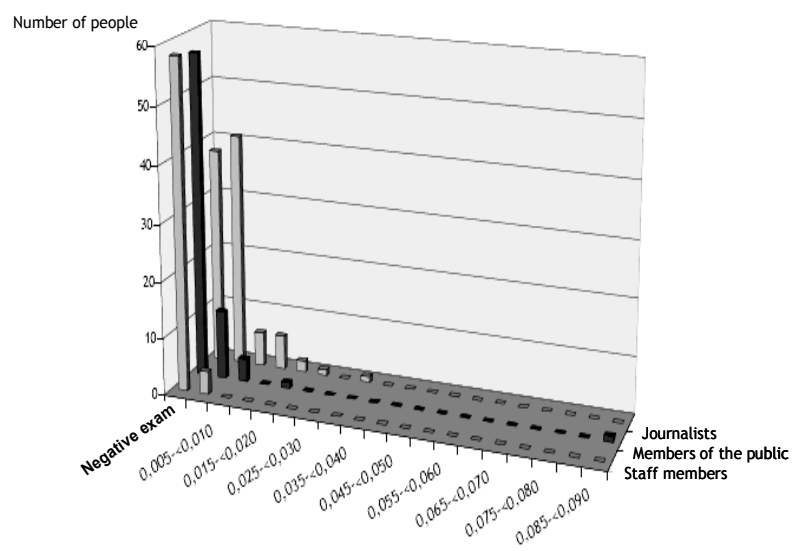

Figure 10. Distribution of committed effective dose (mSv) for people measured between March $11^{\text {th }}$ to April 30 $30^{\text {th }}, 2011$.

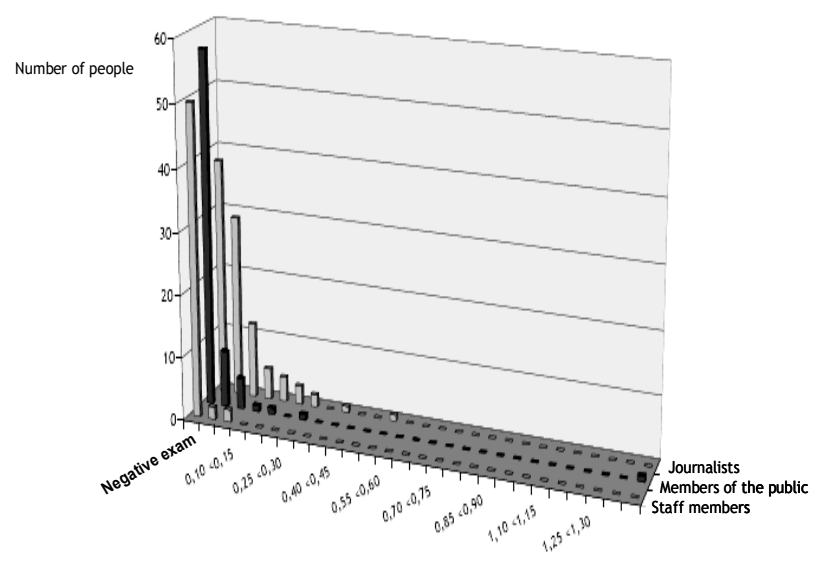

Figure 11. Distribution of equivalent dose to the thyroid (mSv) for people measured between March $11^{\text {th }}$ to April $30^{\text {th }}, 2011$.

\section{Conclusion}

There is an evident need to be prepared to measure rapidly large groups of internally contaminated people. Regardless of the type of the emergency situations - nuclear accident or malevolent use of radiationcasualties will most likely be members of the public and the number of affected people can vary from a few to mass casualties. Furthermore, it is necessary to be able to perform direct measurements on people for reassurance of the public even if such measurements would not be obligatory from a strict radiation protection point of view.

To answer to these issues, a fleet specially designed for radiological accident monitoring of internal contamination has been developed at the IRSN since 2007. It is now in operation since 2010 and capable to control more than 2500 people a day. With their communication network, they are immediately operational, entirely self-contained and thus very well adapted for interventions during a crisis. Furthermore, they can be moved to the measurements sites anywhere in France within 24 hours and be operational in less than two hours.

In the aftermath of the Fukushima accident, the expertise units of this fleet have been used for the control of the contamination of French nationals coming back from Japan. At the end of 2011, the IRSN had carried out 536 in vivo examinations on 268 persons.

From these measurements it has been found that the most important committed effective dose estimated was lower than $0.1 \mathrm{mSv}$ and the equivalent dose to the thyroid lower than $1.4 \mathrm{mSv}$ showing there was no sanitary consequence to the French nationals.

\section{References}

[1] D. Franck, J. Bernière, D. Viltard, F. Parre, C. Challeton-de Vathaire and M. Agarande, Development of two mobile laboratories for routine and accident monitoring of internal contamination. Appl. Radiat. Isot. 70 (2012), pp. 1095-1099.

[2] D. Franck, D. Broggio, D. Viltard, F. Parre, C. Challeton-de Vathaire and M. Agarande, Development of a fleet of intervention mobile unit for radiological accident monitoring of internal contamination, Proceedings of IRPA 13, May 2012, Glasgow (full paper TS2b.5, available at http://www.irpa13glasgow.com/information/downlo ads/).

[3] IRSN, Fukushima, Un An après. Premières Analyses de l'Accident et de ses Conséquences, Rapport IRSN/DG/2012-001 (2012).

[4] JORF, Arrêté du 20 novembre 2009 de l'autorité de sûreté nucléaire du 18 août 2009 relative aux niveaux d'intervention en situation d'urgence radiologique, Journal Officiel de la République Française, 18 décembre 2009, N0293 (2009).

[5] A. Birchall, N.S. Jarvis, M.S. Peace, A.E. Riddell and W.P. Battersby, The IMBA suite: integrated modules for bioassay analysis, Radiat. Prot. Dosim. 79 (1998), pp. 107-110.

[6] International Commission on Radiological Protection, Age-dependent doses to members of the public from intake of radionuclides: part 1. ICRP Publication 56, Annals of the ICRP 20 (2), Pergamon Press, Oxford, (1989).

[7] International Commission on Radiological Protection, Age-dependent doses to members of the public from Intakes of radionuclides: part 2. Ingestion Dose Coefficients. ICRP Publication 67, Annals of the ICRP 23(3/4), Pergamon Press, Oxford, (1993). 